\title{
Editorial
}

\section{Migration, equality and access to health care services}

Equity with respect to health and access of health care should be a major political issue in the contemporary European Community (EC). Most health care systems aim at ensuring the population's good health care according to the individuals' needs, regardless of their social position, gender, race or ethnicity. The Swedish Health Care Act of 1982 states that the goal for health care is to promote "good health and care on equal terms for the entire population". But is this the reality? Does the underprivileged part of the EC population have access, without prejudice, to the care their health status would demand?

To be able to answer these questions, it is necessary to examine what factors decide health, and health care. One of the most influential and persistent associations in public health is between social position and mortality/morbidity, meaning that persons with low social positions have an increased risk of morbidity and premature mortality, compared with those with a high social position. In Sweden, persons with low social position have lower primary health care utilisation than expected, with regard to their actual health status.

Another determinant of health is minority status. The years at the dawn of the third millennium could be characterised as the era of migration. Increased movement of labour in the EC will continue to raise the proportion of immigrants from countries within the EC. Also, the EC is facing an increased migration from North Africa, the Balkans, and the countries of the former Soviet Union. Despite the present restrictions in immigration legislation, new refugees continue to seek asylum because of persecution, war, or environmental disasters.

People who migrate from their country of birth to another country, or even another part of the world, are generally healthier than those who do not. However, this "healthy migrant effect" tends to wear off with time. ${ }^{2}$ Forced migration means losing social, cultural, and economic connections with one's country of origin. It also includes the encounter with a different society, a different language, and the gradual adaptation to a new culture. Furthermore, many refugees are unemployed, live in deprived neighbourhoods, and have an increased risk of ethnic and social vulnerability that influences their health negatively. ${ }^{3}$ Thus, immigrants are under strong pressure in the sociocultural segment of life where they live and work.

Growing evidence has been presented that both migration status, defined as being born abroad, and low social position are independent risk factors associated with poor health. ${ }^{4}$ Labour migrants from Finland and southern Europe, and refugees from non-European countries had high risks of long term illness, which only partly could be explained by material deprivation or a sedentary lifestyle. ${ }^{5}$ In contrast, another study recently published in this journal demonstrated that Yugoslavian labour migrants and refugees from Arab countries had high odds ratios of poor self reported health, compared with the Swedish reference group, that largely could be explained by disadvantaged socioeconomic conditions. ${ }^{6}$ The US medical services data, or population surveys, generally document the expected pattern of minority disadvantage for African Americans and Hispanic Americans. ${ }^{78}$ There is little evidence that refugees live, despite being highly educated, in a marginal social and cultural sector in society. Moreover, they seem to have a double burden with the effect of ethnic minority status and low social position on their health. In contrast, there is scarce evidence on whether ethnic minorities in Europe today overuse or underuse health care services.

Furthermore, there are different patterns of poor health status in different ethnic groups. It has been suggested that cultural differences between ethnic groups may imply that they perceive their combined physical and psychological health differently. ${ }^{9}$ However, the association between health status and mortality seems to be universal rather than culturally determined. For example, there was a strong association between self reported health in different ethnic groups in the US and the total mortality of these ethnic groups. ${ }^{10}$

In this edition of the journal, the article by Karen Stronks and coauthors, ${ }^{11}$ focusing on the Surinamese, the Netherlands Antilleans, Turkish and Moroccan immigrant population in Amsterdam, adds important new knowledge to the international literature of migration medicine, and bridges a gap. The authors demonstrate a lower utilisation of more specialised health care for immigrant groups in the Netherlands, particularly for Turkish and Moroccan immigrants. This lower utilisation remained, even after having taken actual need (health status) and social position into consideration. The authors' analysis indicates that low social position "only partly explains the lower utilisation of these services among immigrant groups. This suggests that ethnic background in itself may account for patterns of consumption, potentially because of limited access."

There is an increasing interest in studying the need of health care services, health and health care utilisation in ethnic minorities in the EC. One important reason is the ongoing transformation-in the Netherlands, Germany, UK, Sweden and other countries-to multicultural and multiethnic communities. For example, Sweden has more than one million foreign born inhabitants, and in December $200011.3 \%$ of the population was born abroad. The continuously rising proportion of poeple born abroad has made the health and use of health care services of different ethnic groups increasingly important in a public health perspective. However, the absence of representative and comparative data on self reported health status, use of health care services and data about attitudes and perceived discrimination in ethnic minorities in the EC, limits our knowledge about the burden of poor health, and about the possibility of prejudice in health care. There is a need for more studies such as that by Stonks et al in the contemporary EC that disentangle the complex associations between social position, ethnic minority status, health status and health care utilisation.

Karolinska Institutet, Sweden

JAN SUNDQUIST

\footnotetext{
Haglund B, Rosen M. [The welfare wall is cracked. Low-educated people are not favoured by health services]. Lakartidningen 1996;93:3672, are not

2 Williams R. Health and length of residence among south Asians in Glasgow: a study controlling for age. F Public Health Med 1993;15:52-60.
} 
3 Sundquist J, Bayard-Burfield L, Johansson LM, et al. Impact of ethnicity, violence and acculturation on displaced migrants: psychological distress and psychosomatic complaints among refugees in Sweden. $\mathcal{F}$ Nerv Ment Dis 2000;188:357-65.

4 Sundquist J. Ethnicity, social class and health. A population-based study on the influence of social factors on self-reported illness in 223 Latin American refugees, 333 Finnish and 126 south European labour migrants and 841 Swedish controls. Soc Sci Med 1995;40:777-87.

5 Sundquist J, Johansson S-E. Long-term illness among indigenous and foreign-born people in Sweden. Soc Sci Med 1997;44:189-98.

6 Lindstrom M, Sundquist J, Ostergren PO. Ethnic differences in self reported health in Malmo in southern Sweden. F Epidemiol Community Health 2001; 55:97-103.
7 Mueller KJ, Ortega ST, Parker K, et al. Health status and access to care among rural minorities. F Health Care Poor Underserved 1999;10:230-49.

8 Park J, Buechner JS. Race, ethnicity, and access to health care, Rhode Island, 1990. F Health Soc Policy 1997;9:1-14.

9 Shetterly SM, Baxter J, Mason LD, et al. Self-rated health among Hispanic vs non-Hispanic white adults: the San Luis Valley Health and Aging Study. Am 7 Public Health 1996;86:1798-801.

10 McGee DL, Liao Y, Cao G, et al. Self-reported health status and mortality in a multiethnic US cohort. Am f Epidemiol 1999;149:41-6.

11 Stronks K, Ravelli ACJ, Reijneveld SA. Immigrants in the Netherlands: Equal access for equal needs? F Epidemiol Community Health2001;55: $701-7$.

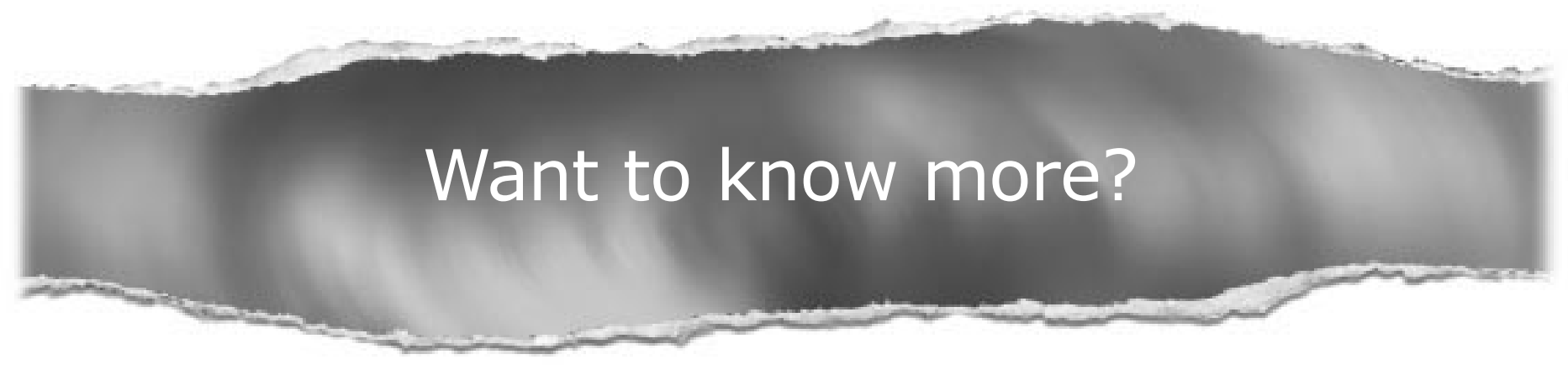

Data supplements

Limited space in printed journals means that interesting data and other material are often edited out of articles; however, limitless cyberspace means that we can include this information online. Look out for additional tables, references, illustrations.

www.jech.com 